\title{
PEMANFAATAN KARBON AKTIF AMPAS TAHU TERAKTIVASI NaCI SEBAGAI PENYERAP ZAT WARNA CONGO RED
}

\section{[The Utilization of Activated Carbon From Tofu Dregs Activated With Sodium Chloride As The Adsorbent Of Congo Red Dye]}

\author{
Sutomo Eka Putra ${ }^{{ }^{\star}}$, Khairuddin ${ }^{1}$, Dwi Juli Puspitasari ${ }^{1}$, Husain Sosidi ${ }^{1}$ \\ 1) Jurusan Kimia, Fakultas MIPA, Universitas Tadulako, Palu \\ Jl. Soekarno Hatta Km.9, Kampus Bumi Tadulako Tondo Palu, Telp. 0451- 422611
}

*)Coresponding author:ekhaputra77@gmail.com(085230938179)

Diterima 14 Desember 2018, Disetujui 12 Maret 2019

\begin{abstract}
The utilization of activated carbon from tofu dregs activated with sodium chloride as the adsorbent of congo red dye has been done. This research aims to determine the ability of activated carbon from tofu dregs activated with sodium chloride in adsorbing congo red dye. This researchused a compeletely randomized design with 3 independent variables, are the concentration of activator, contact time, and $\mathrm{pH}$, and the dependent variable was an adsorption percentage of congo red dye. The results show that the activated carbon from tofu dregs activated with sodium chloride can highly adsorb the congo red dye with three molar of sodium chloride within 60 minutes at $\mathrm{pH} 2$. Itsuggests that the tofu dregs can be utilized as an activated carbon.
\end{abstract}

Keywords: Activated Carbon, Tofu Waste, Congo Red Dye, Adsorption

\section{ABSTRAK}

Telah dilakukan penelitian mengenai pemanfaatan karbon aktif ampas tahu teraktivasi $\mathrm{NaCl}$ sebagai penyerap zat warna Congo Red. Penelitian ini bertujuan untuk mengetahui kemampuan karbon aktif ampas tahu teraktivasi $\mathrm{NaCl}$ dalam menyerap zat warna Congo Red. Penelitian ini menggunakan rancangan acak lengkap dengan tiga variabel bebas yaitu konsentrasi aktivator, waktu kontak dan $\mathrm{pH}$ sedangkan variabel terikat yaitu persentase Congo Red yang terjerap. Hasil penelitian menunjukkan penyerapan terbaik diperoleh pada karbon aktif ampas tahu teraktivasi $\mathrm{NaCl} 3 \mathrm{M}$ dengan waktu kontak optimum selama 60 menit pada kondisi $\mathrm{pH}$ 2. Dari penelitian ini diketahui bahwa limbah ampas tahu dapat dimanfaatkan menjadi karbon aktif.

Kata kunci: Karbon Aktif, Ampas Tahu, Zat Warna Congo Red, Adsorpsi 


\section{LATAR BELAKANG}

Perkembangan pembangunan di sektor industri semakin cepat.Hal ini berdampak terhadap peningkatan taraf kehidupan masyarakat. Dampak negatif dari pembangunan adala bertambahnya limbah yang dihasilkan. Limbah yang dihasilkan dapat berupa limbah cair atapun padat.Salah satu limbah cair yang dihasilkan dari kegiatan industri adalah zat warna yang dapat mencemari air. Industri tekstil merupakan salah penyumpang limbah cair terbesar di Indonesia yang umumnya mengandung 750 ppm zat tersuspensi (Pratiwi, 2010). Zat warna yang umum digunakan oleh industri tekstil adalah Congo Red. Congo Redyang memiliki potensi berbahaya bagi manusia.Senyawa ini dapat menyebahkan mual pada lambung, muntah dan diare.Bila terpapar senyawa ini dengan waktu yang cukup lama dapat menyebabkan gangguan sistem pernapasan, gangguan reproduksi dan janin serta dapat memicu terjadinya kanker (Prahl, 2002). Zat warna ini sangat mudah larut dalam air dan tidak dapat didegradasi secara biologi (Catanho, 2006).

Pengolahan limbah cair dengan berbagai metode, seperti menggunakan lumpur aktif, koagulasi-flokulasi, dan metode lainnya. Salah satu metode yang sering digunakan adalah metode adsorpsi. Proses adsorpsi adalah proses penyerapan dimana zat yang terserap terikat pada permukaan partikel adsorben
(Mattel, 1991). Adsorben yang dapat digunakan antara lain adalah karbon aktif, zeolit, bentonit, kitosan dan bahan bahan lainnya yang memiliki aktivitas untuk menyerap suatu zat kimia seperti ampas tahu. Ampas tahu hanya diguankan oleh petani sebagai pakan ternak dan bahan baku dalam pembuatan tempe gembus. Terdapat potensi lain untuk pemanfaatan ampas tahu, yaitu sebagai adsorben. Nohong (2010) melaporkan bahwa 1000 mg ampas tahu mampu menyerap logam krom hingga $100 \%$ dan logam besi 95,53 $\%$ dengan waktu kontak 150 menit. Hal ini menunjukkan bahwa adsorpsi dengan limbah ampas tahu memerlukan konsentrasi adsorben yang tinggi dan waktu yang relatif lama. Masalah ini dapat diatasi dengan cara mengubah limbah ampas tahu menjadi karbon aktif.

Karbon aktif adalah arang yang dihasilkan melalui proses aktivasi untuk memperbesar pori-pori agar daya serapnya meningkat. Aktivasi karbon aktif secara kimia dilakukan dengan menambahkan bahan kimia, seperti senyawa garam $\mathrm{NaCl}$. $\mathrm{NaCl}$ bersifat dehidrat sehingga $\mathrm{NaCl}$ dapat menghambat permbentukan tar. Tar yang terbentuk dapat menutup pori-pori karbon aktif sehingga daya adsorpsinya menurun (Mu'jizah, 2010). Gimbal, et al. (2009) telah mengkaji adsorben karbon aktif dari buah khaya senegalensis yang diaktivasi dengan teraktivasi $\mathrm{NaCl}$ menunjukkan daya adsorpsi yang lebih besar 
dibandingkan karbon aktif dari buah khaya yang diaktivasi dengan zat kimia lain.

Penggunaan $\mathrm{NaCl}$ sebagai aktivator telah dilakukan dalam beberapa penelitian. Mu'jizah (2010) melaporkan bahwa $\mathrm{NaCl} 30 \%$ dapat mengaktivasi secara optimal karbon aktif dengan daya serap 575 mg/g. Mirwan (2005) juga telah mendapatkan bahwa karbon aktif terbaik dihasilkan pada konsentrasi $15 \%$ dengan waktu perendaman 10 jam. Hartini, et al.., (2014) melalui pengujian menggunakan SEM menjelaskan bahwa karbon aktif dengan aktivator $\mathrm{NaCl}$ 10\% memiliki poripori yang lebih banyak dan lebih dalam sehingga memiliki daya serap yang lebih besar. Berdasarkan hal ini maka perlu dilakukan penelitian mengenai pemanfaatan limbah ampas tahu sebagai karbon aktif teraktivasi $\mathrm{NaCl}$ untuk penyerapan zat warna Congo Red.

\section{METODE PENELITIAN}

\section{Bahan dan Peralatan}

Bahan dasar yang digunakan dalam penelitian ini adalah zat warna congo red, padatan $\mathrm{NaCl}$, Larutan $\mathrm{NaOH} 0,1 \mathrm{~N}$ dan larutan HCL $0,1 \mathrm{~N}$.

Peralatan yang digunakan adalah seperangkat alat gelas, neraca analitik, spatula, desikator, ayakan 60 mesh, tanur, $\mathrm{pH}$ meter, cawan porselen, dan spektrofotometer UV-Vis.

\section{Prosedur Penelitian}

Preparasi Sampel (Hartini et al., 2014)

Ampas tahu basah dijemur hingga kadar airnya berkurang, lalu dikeringkan dengan oven dengan suhu $105^{\circ} \mathrm{C}$ hingga kering. Setelah itu ampas tahu kering dikarbonasi pada suhu $300^{\circ} \mathrm{C}$ selama 1 jam.Karbon yang terbentuk kemudian dihaluskan lalu diayak dengan ayakan 60 mesh.

\section{Adsorpsi Zat Warna Congo Red dengan Variasi Konsentrasi Aktivator (Hartini et al., 2014)}

Karbon ampas tahu yang telah halus direndam dengan larutan $\mathrm{NaCl}$ dengan konsentrasi masing-masing $1 \mathrm{M}, 2 \mathrm{M}, 3 \mathrm{M}$, $4 \mathrm{M}$, dan $5 \mathrm{M}$. selama 24 jam. Karbon aktif sebanyak 0,5 gram dicampurkan dengan zat warna Congo Red 500 ppm sebanyak $5 \mathrm{~mL}$ lalu didiamkan selama 20 menit. Selanjutnya filtratnya diambil dan diukur menggunakan spektrofotometer UV-Vis.

\section{Adsorpsi Zat Warna Congo Red dengan Variasi Waktu Kontak (Gultom dan Lubis, 2014) \\ Karbon aktif teraktivasi $\mathrm{NaCl} 3 \mathrm{M}$} sebanyak 0,5 gram dicampurkan dengan larutan Congo Red 500 ppm sebanyak 5 $\mathrm{mL}$ dan dibiarkan selama $20,40,60,80$, dan 100 menit. Selanjutnya campuran disaring lalu diambil filtratnya dan diukur menggunakan spektrofotometer UV-Vis.

\section{Adsorpsi Zat Warna Congo Red dengan Variasi pH (Gultom dan Lubis, 2014)}

Karbon aktif teraktivasi $\mathrm{NaCl} 3 \mathrm{M}$ sebanyak 0,5 gram dicampurkan dengan zat warna Congo Red pada $\mathrm{pH}$ 2, 4,6, 8 dan 10 selama 60 menit. Campuran kemudian disaring lalu diambil filtratnya dan diukur menggunakan spektrofotometer UV-Vis. 


\section{HASIL DAN PEMBAHASAN}

Pembuatan karbon aktif melalui 2 tahapan yaitu melalui proses karbonasi dan aktivasi. Karbonasi merupakan upaya untuk mengasilkan arang menggunakan panas. Proses karbonasi pada limbah ampas tahu dilakukan pada tempat tertutup untuk menghindari hilangnya karbon dari ampas tahu membentuk gas $\mathrm{CO}_{2}$. Proses karbonasi ampas tahu menggunakan suhu $300^{\circ} \mathrm{C}$ selama 60 menit. Proses karbonasi yang lebih lama dapat mengahsilkan gas $\mathrm{CO}_{2}$.

Pembuatan karbon aktif tidak lepas dari proses aktivasi yang bertujuan untuk membuka, menambah atau mengembangkan volume pori dan memperbesar diameter pori yang telah terbentuk pada proses karbonisasi. Aktivasi dilakukan secara kimia menggunakan larutan $\mathrm{NaCl}$ sebagai aktivator.Karbon aktif ampas tahu yang teraktivasi $\mathrm{NaCl}$ diaplikasikan sebagai penyerap zat warna Congo red. Congo Red memiliki serapan maksimum pada panjang gelombang $499 \mathrm{~nm}$. Menurut Christian (2003), panjang gelombang maksimum Congo Red adalah 497 nm. Adapun kurva standar zat warna Congo Red memiliki persamaan regresi $\mathrm{y}=$ $0,0375 X-0,0117$ dengan nilai $R^{2}=$ 0,9995 .

Pengaruh Konsentrasi Aktivator Terhadap Adsorpsi Zat Warna Congo Red.

Kemampuan adsorpsi suatu penyerap didasarkan pada banyak hal, diantaranya adalah konsentrasi aktivator yang digunakan. Konsentrasi aktivator menentukan banyaknya jumlah pori yang terbentuk pada karbon aktif. Proses aktivasi dari suatu karbon dapat mengubah bentuk dari karbon. Penelitian yang dilakukan Hartini et al. (2014) menunjukkan bahwa karbon yang teraktivasi memiliki pori-pori yang lebih banyak dibanding karbon yang tidak teraktivasi.

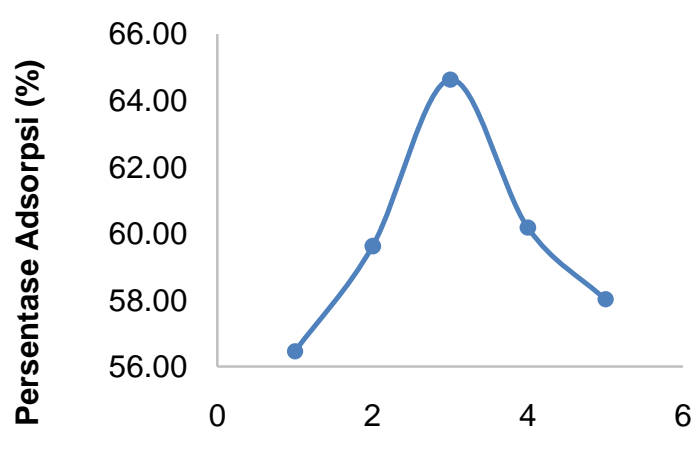

Konsentrasi Aktivator (M)

Gambar 1 Grafik pengaruh konsentrasi aktivator terhadap adsorpsi zat warna Congo red.

Konsentrasi $\mathrm{NaCl} 1 \mathrm{M}, 2 \mathrm{M}$ dan $3 \mathrm{M}$ mengalami peningkatan penyerapan zat warna Congo Red dengan persentase adsorpsi tertinggi pada konsentrasi $\mathrm{NaCl} 3$ M sebesar 64,62\% (Gambar 1). Namun pada karbon aktif ampas tahu dengan konsentrasi $\mathrm{NaCl} 4$ dan $5 \mathrm{M}$, penyerapan zat warna Congo Red mengalami penurunan. Larutan dengan konsentrasi $\mathrm{NaCl}$ yang tinggi memiliki jumlah partikel yang lebih banyak. Hai inilah yang menyebabkan terjadinya halangan sterik pada proses adsorpsi yang berlangsung. 


\section{Pengaruh Waktu Kontak Terhadap Adsorpsi Zat Warna Congo Red.}

Faktor lain yang mempengaruhi daya adsorpsi suatu adsorben ialah waktu kontak. Waktu kontak yang lebih lama akan menyebabkan jumlah adsorbat yang teradsorpsi semakin banyak karena semakin banyak partikel adsorben yang berinteraksi dengan adsorbat. Penentuan waktu kontak dapat memberikan informasi berapa lama waktu yang diperlukan untuk mencapai penyerapan optimum.

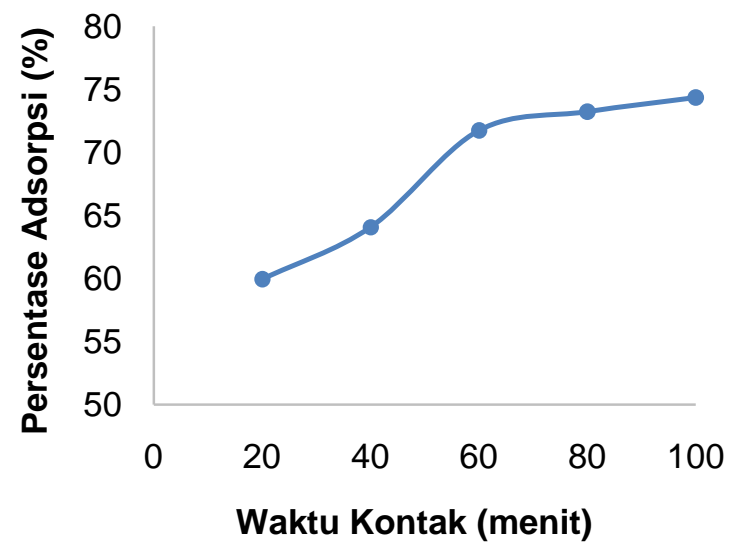

Gambar 2. Pengaruh waktu kontak terhadap adsorpsi zat warna Congo Red.

Terjadi peningkatan penyerapan zat warna Congo Red seiring bertambahnya waktu kontak (Gambar 2). Hal ini disebabkan tumbukan antar partikel terus terjadi seiring pertambahan waktu.Hal ini sesuai dengan pendapat Nwabanne and Igbokwe (2011), dimana jumlah adsorbat yang terserap semakin bertambah dengan waktu kontak antara adsorbat dan adsorben. Grafik 4.2 juga menunjukkan bahwa penyerapan maksimum terjadi pada waktu kontak 60 menit dengan presentasi adsorpsi sebesar $71,71 \%$.

\section{Pengaruh pH Terhadap Adsorpsi Zat Warna Congo Red.}

Faktor yang mempengaruhi suatu adsorpsi salah satunya adalah pH. Dalam proses adsorpsi, $\mathrm{pH}$ mempengaruhi ionisasi adsorbat. Variasi $\mathrm{pH}$ digunakan dengan cara menambahkan larutan $\mathrm{HCl}$ $0,1 \mathrm{M}$ dan larutan $\mathrm{NaOH} \quad 0,1 \mathrm{M}$.

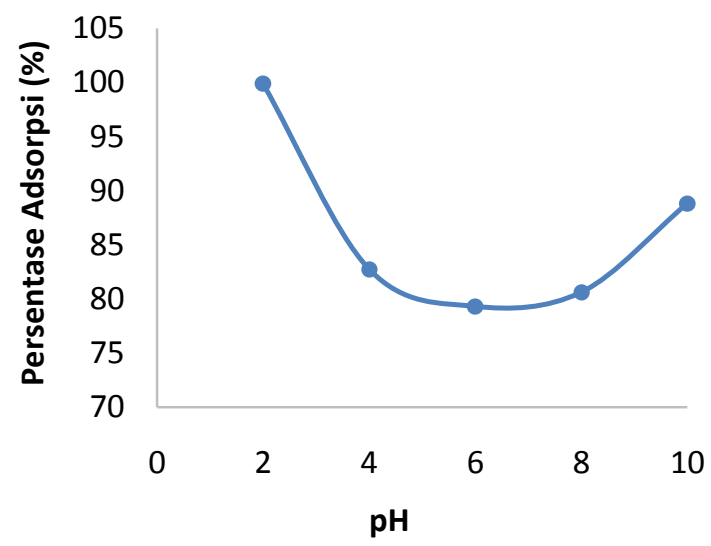

Gambar 3. Pengaruh pH Terhadap Adsorpsi zat warna Congo Red.

Terjadi penyerapan zat warna yang mengalami penurunan pada $\mathrm{pH}$ mendekati netral namun pada $\mathrm{pH}$ tinggi dan $\mathrm{pH}$ rendah penyerapan yang terjadi mengalami peningkatan. Penyerapan tertinggi ditunjukkan pada $\mathrm{pH} 2$ dengan presentasi adsorpsi hampir mencapai $100 \%$ (Gambar 3). Hal ini menjelaskan bahwa penyerapan zat warna Congo Red menggunakan karbon aktif ampas tahu terjadi adsorpsi secara kimia. Hal serupa ditunjukkan pada penelitian yang dilakukan Gultom dan Lubis (2014) dimana penyerapan logam $\mathrm{Pb}$ dan $\mathrm{Cd}$ terbaik pada $\mathrm{pH} 3$ dan 4. Pada 
$\mathrm{pH} 2$, banyak ion $\mathrm{Cl}^{-}$yang mengelilingi karbon aktif sehingga zat warna Congo Red yang merupakan zat warna kationik lebih banyak yang berikatan dengan karbon aktif ampas tahu. Pada pH 10 penyerapan zat warna Congo Red cukup tinggi dipengaruhi oleh ion $\mathrm{OH}^{-}$ dari $\mathrm{NaOH}$ yang mengelilingi karbon aktif ampas tahu (Bernasconi et al, 1995).

\section{KESIMPULAN}

Ampas tahu dapat dimanfaatkan menjadi karbon aktif untuk menyerap zat warna congo red dengan penyerapan terbaik ditunjukkan oleh karbon aktif dengan konsentrasi $\mathrm{NaCl} 3 \mathrm{M}$, dengan waktu kontak 60 menit, pada pH 2.

\section{DAFTAR PUSTAKA}

Bernasconi, G.,Gerster, H., Hauser, H. 1995. Teknologi Kimia Bagian 2 Edisi Pertama. Jakarta: Pradnya Paramitha.

Catanho, M. 2006. Avaliacao Dos Tratamentos Electroquimico $\mathrm{E}$ Fotoeletroquimico $\mathrm{Na}$ Degradacao De Corantes Texteis.Quim Nova 29(5).

Christian, G.D. 2003. Analytical Chemistry 6th edition. New York: John Willey\& Sonc Inc.

Gimbal, C, E., Ocholi, O., Egwaikhide, P, A., Muyiwa, T., and Emmanuel, E,A. 2009. Methylene Blue Adsorption on Activated Carbon Prepared From Khaya Seneagelis Fruits. New Raw Material for Activated Carbon $I$. Cien.Inv.
Gultom E.M., dan Lubis M.T. 2014. Aplikasi Karbon Aktif Dari Cangkang Kelapa Sawit Dengan Aktivator $\mathrm{H}_{3} \mathrm{PO}_{4} \quad$ Untuk Penyerapan Logam Berat $\mathrm{Cd}$ dan $\mathrm{Pb}$. Jurnal Teknik Kimia USU 3 (1).

Hartini L., Yulianti E., dan Mahmuda R. 2014. Karakterisasi Karbon Aktif Teraktivasi NaCl Dari Ampas Tahu. Alchemy Vol 3 (2):145-153.

Mattel, C.L. 1991. Adsorption $2^{\text {nd }}$ Edition. New York: McGraw-Hill Company Inc.

Mirwan, M. 2005. Daur Ulang Limbah Hasil Industri Gula (Ampas Tebu/ Bagasse) dengan Proses Karbonasi Sebagai Karbon Aktif. Jurnal Rekayasa Perencanaan 1(3).

Mu'jizah, S. (2010). Pembuatan dan Karakterisasi Karbon Aktif dari Biji Kelor (Moringa oleifera L.) dengan $\mathrm{NaCl}$ sebagai Bahan Pengaktif. Skripsi. Malang: UIN Maulana Malik Ibrahim.

Nohong. 2010. Pemanfaatan Limbah Tahu Sebagai Bahan Penyerap Logam Krom, Kadmium dan Besi Dalam Air Lindi TPA. Jurnal Pembelajaran Sains 6: 257-269.

Nwabanne, J T., Igbokwe P. K. 2011. Preparation of Activated Carbon from Nipa Palm Nut:Influence of Preparation Condition, ResearchJournal of Chemical Sciences, 1: 53-58,

Prahl A, Derdowska I, Dawidowska O, Neubert K, Hartrodt B, Wierzba T, Juzwa W, Lammek B. 2002. New analogues of bradykinin substituted in the C-terminal part of the moleculewith naphthylalanine. Polish J Chem 76:1433-1439 
Pratiwi, Y. 2010. Penentuan Tingkat Pencemaran Limbah Industri Tekstil Berdasarkan Nutriton Value Coeficient Bioindikator. Jurnal Teknologi 3: 129-137. 